\title{
Complex radial polydactyly in a Chinese family: inclusion of triphalangism, triplication, and syndactyly
}

\author{
Jihai Xu ${ }^{1 \#}$, Xiaokun Chen ${ }^{2 \#}$, Xiaofeng Teng ${ }^{1}$, Xin Wang $^{1}$, Hong Chen ${ }^{1}$ \\ ${ }^{1}$ Hand Surgery Department, Ningbo No. 6 Hospital, Ningbo, China; ${ }^{2}$ Department of Orthopedic Trauma, Peking University People Hospital, \\ Beijing, China \\ Contributions: (I) Conception and design: J Xu; (II) Administrative support: H Chen; (III) Provision of study materials or patients: J Xu, X Teng; (IV) \\ Collection and assembly of data: X Wang; (V) Data analysis and interpretation: X Chen; (VI) Manuscript writing: All authors; (VII) Final approval of \\ manuscript: All authors. \\ \#These authors contributed equally to this work. \\ Correspondence to: Xin Wang, MM; Hong Chen, MM. Hand Surgery Department, Ningbo No. 6 Hospital, No. 1059 Zhongshan East Road, Yinzhou \\ District, Ningbo 315040, China. Email: dr.wangxin@qq.com; chenhong6612@163.com.
}

\begin{abstract}
Background: Few studies have investigated families in which multiple individuals over three or more generations are affected by radial polydactyly and syndactyly. This report describes an extremely rare family in which nine individuals across six generations were affected by complex radial polydactyly.

Methods: We investigated a six-generation pedigree with radial polydactyly including triplication, triphalangism, hypoplasia, and symphalangism. There was a total of 34 individuals (including their spouses) in the family and 11 individuals had polydactyly. The average age of the patients ranged from 7 months to 96 years. The characteristic feature of the malformation in these patients was described. Two patients underwent surgical resection for radial supernumerary thumbs. The Bilhout-Cloquet technique and On-topplasty technique were used to reconstruct the nail and the joints.

Results: The patients in this family presented with thumb duplication and triphalangism in both hands, including a variety of deformities, such as triplication, triphalangism, hypoplasia, and symphalangism. Syndactyly and ulnar polydactyly were also frequently observed. Two patients who underwent surgical treatment showed good hand and thumb function at the 8- and 2-year post-operative follow-up, respectively. Conclusions: The present study reported various mixed phenotypes including triplication, triphalangism, hypoplasia, and symphalangism within the same family which may represent a rare type of polydactyly. Surgical resection of extra digits to achieve mobility of the thumb is the main treatment option for radial polydactyly. Given the ulnar thumb is better developed, the radial thumb is typically resected in patients with radial polydactyly. These reconstructive principles are fit for this Chinese family as well.
\end{abstract}

Keywords: Polydactyly; syndactyly; phenotype

Submitted Apr 02, 2021. Accepted for publication Aug 01, 2021.

doi: $10.21037 /$ atm-21-2773

View this article at: https://dx.doi.org/10.21037/atm-21-2773

\section{Introduction}

Polydactyly is characterized by duplication of digits ( $>5$ digits per limb) (1). Polydactyly results from disturbances in the normal programme of the anterior-posterior axis of the developing lim. It is usually a heterogeneous inherited limb disorder, which is associated with a wide variety of phenotypes ranging from simple bifid duplication to complex duplications. Variations in phenotype include different sites (hand or foot), different location of the extra digits (radial side, ulnar side, or central), and severity (partial or complete duplication of the digits) (2).

Radial polydactyly, also called preaxial polydactyly, that is accompanied by duplication of the thumb, is one of the most commonly reported forms of polydactyly with an incidence 


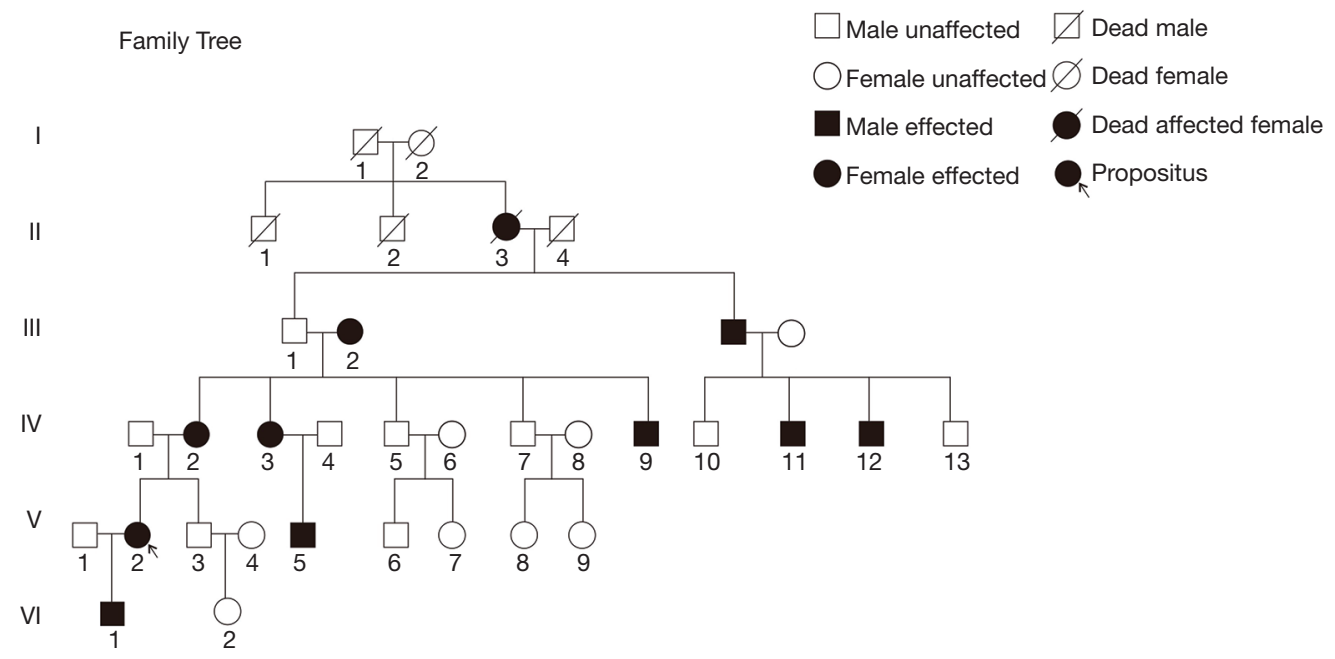

Figure 1 The pedigree of the 6-generation Chinese family. There were 11 affected family members (6 men and 5 women) and 23 unaffected individuals.

of approximately 1 in 3,000 births (3). In Zhou et al.'s study, they investigated the epidemiological characteristics of Chinese polydactyly and identified 2,097 cases presented with polydactyly in $2,218,616$ perinates, which the prevalence was 9.45 per 10,000 (4). The main treatment for radial polydactyly is surgical removal of the extra digits to preserve thumb function (5). A limited number of studies have investigated families in which multiple individuals in the same family across three generations or more are affected by radial polydactyly and syndactyly.

Previous study reported 9 patients from 9 families, and found there was an association between radial polydactyly and radial longitudinal deficiency (RLD) in these patients. Similar phenotype was also identified in the family of our study (6).

The present study report examined an extremely rare family in which nine individuals across six generations were affected by complex radial polydactyly. The various mixed phenotypes profiled in this family may represent a rare type of polydactyly, which should be caused by the same genetic background.

We present this article in accordance with the MDAR reporting checklist (available at https://dx.doi.org/10.21037/ atm-21-2773).

\section{Methods}

\section{Patients}

All procedures performed in this study involving human participants were in accordance with the Declaration of Helsinki (as revised in 2013). The study was approved by the Ethical Review Committee of the Ningbo No. 6 Hospital (SX201950) and informed consent was taken from all the patients.

A pedigree of a six-generation Chinese family was involved (Figure 1). There was a total of 34 individuals (including their spouses) in the family and 11 individuals had polydactyly. The average age of the patients ranged from 7 months to 96 years. Among the 11 patients with polydactyly, 6 were male and 5 were female, and the male to female ratio was approximately $1: 1$. The affected individuals spanned 5 generations, and there was no skipped generation. All affected patients had one affected parent, which suggested that the condition had an autosomal dominant pattern of inheritance. Except for 2 patients (II3 and III2) who were deceased at the time of this study, all patients underwent complete physical examination, and clinical information including photographs and $\mathrm{X}$-ray films were collated.

\section{Surgical treatment}

Two patients (V2 and VI) underwent surgical treatment for restoration of hand function. We traced all the family members and found nine individuals across six generations were affected by complex radial polydactyly. All other adult patients were accustomed to the appearance and function of their hands and refused to undergo surgical treatment. Patient V2 was a 25-year-old right-handed woman who 

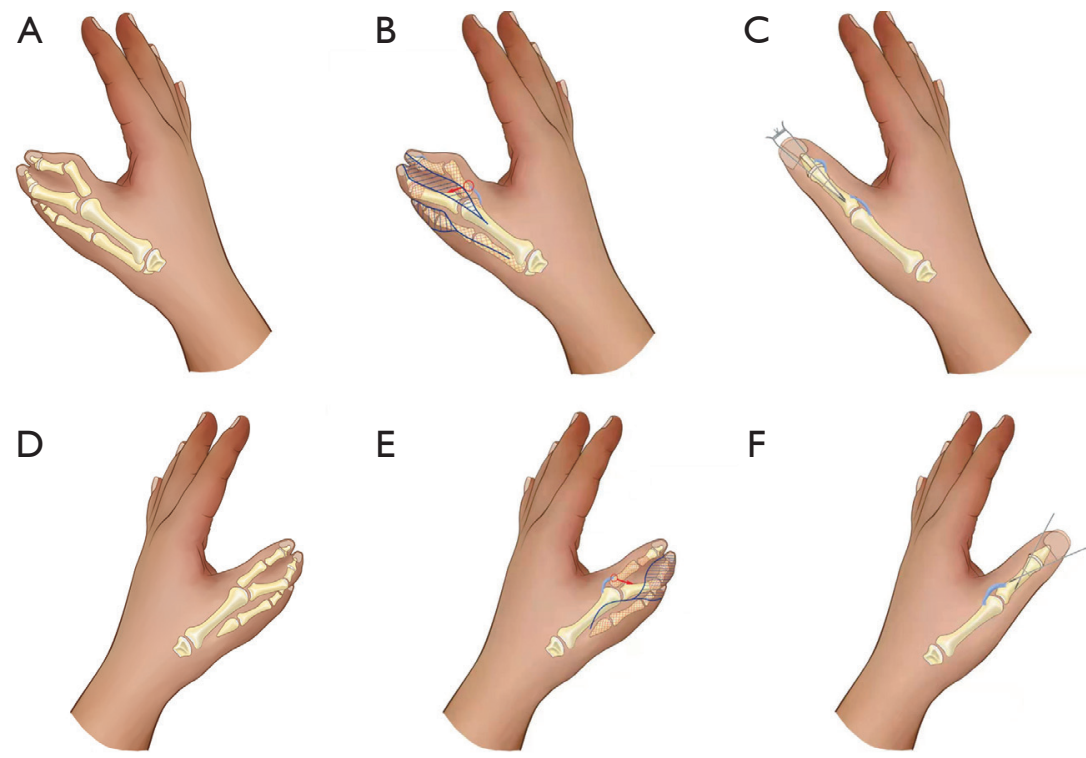

Figure 2 Diagrammatic representation of the surgical procedure in the 25 -year-old woman (Patient V2). (A-C) right hand; (D-F) left hand.

underwent two surgical operations in 2010. The first surgery was performed on May 20, 2010. Osteotomy was performed to resect the radial supernumerary thumb with preservation of the middle and ulnar supernumerary thumbs. A tongue-shaped flap was used to repair the skin defect (Figure 2A). Subsequently, a second osteotomy was performed to resect the ulnar supernumerary thumb with preservation of the radial supernumerary thumb (Figure 2B). The distal and middle phalanges and half of the proximal phalanges were removed from the ulnar supernumerary thumb with the preservation of the surrounding skin and soft tissues, nails, and interphalangeal joint (Figure 2C). The Bilhout-Cloquet technique was used to reconstruct the nail and the joints, followed by reconstruction of the capsule and ligaments surrounding the metacarpophalangeal and distal interphalangeal joints. The second surgery for the left hand was performed on August 5, 2010. An arc incision was made from the distal end of the dorsal thumb to the middle of the metacarpus (Figure 2D). Osteotomy was performed to resect the radial supernumerary thumb with preservation of the middle and ulnar supernumerary thumbs (Figure 2E). On-top-plasty technique was used to reconstruct the metacarpophalangeal joint, followed by reconstruction of the ulnar collateral ligament and capsule (Figure 2F).

\section{Statistical analysis}

Descriptive statistics, summarizing data in an organized manner, were used and reported numerically in the text and/or in the figures and tables.

\section{Results}

\section{Characteristics of the pedigree}

The characteristic feature of the malformation in these patients was radial polydactyly associated with various phenotypes including thumb duplication, syndactyly, triphalangism, and ulnar polydactyly. As shown in Figure 3, all affected patients had malformations in both hands, and most exhibited a mixed phenotype. Out of the 9 affected patients, there were 7 cases of radial polydactyly including triplication (except patients IV9 and V5), and 8 cases of triphalangeal thumb (except patient V5; Table 1). Thus, the patients in this family had complex radial polydactyly with various mixed phenotypes including triplication, triphalangism, and hypoplasia. Syndactyly was observed in 6 of the 9 affected patients (except patients III2, IV2, and V2) and ulnar polydactyly was noted in 2 patients.

\section{Description of the phenotype}

The patients with complex thumb duplication had a variety of deformities, including triplication, triphalangism, hypoplasia, and symphalangism (Figure 4). Members of this family commonly had a combination of these deformities. 


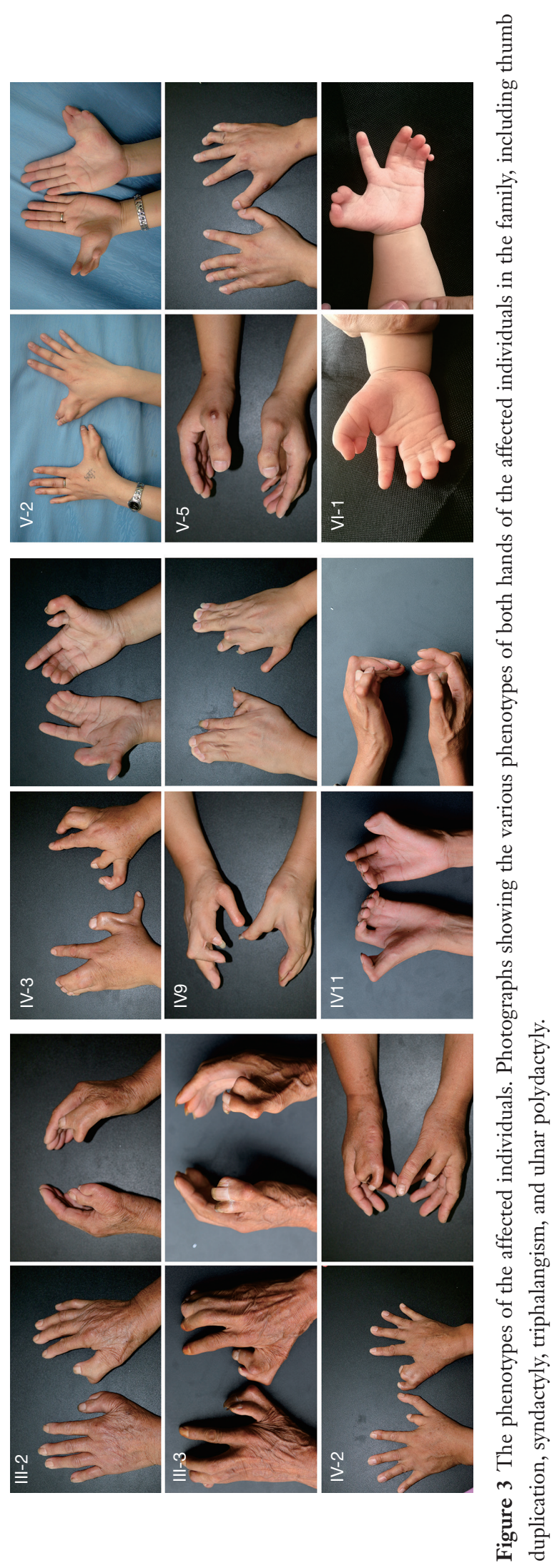

In addition, syndactyly manifested as complex and simple incomplete types (Figure 5). In complex syndactyly, the lesions involved fusion of both bony and soft tissue and commonly affected the third to the fifth digits. In simple incomplete syndactyly, the malformation involved incomplete fusion of the body or soft tissue between the third and fourth digits.

\section{Postoperative recovery}

The 2 patients who were surgically treated were followed up for 8 and 2 years, respectively. One of the patients (patient V2) showed normal hand and thumb function at the followup at 8 years after the surgery, and the $\mathrm{X}$-ray showed normal anatomical configuration in both hands (Figure 6). Similarly, the other patient (VI) showed satisfactory recovery of hand function at the 2-year follow-up post-surgery (Figure 7).

\section{Discussion}

Classification of radial polydactyly is useful for planning surgical treatment and evaluation of surgical outcomes. Although radial polydactyly is a common congenital hand condition with an autosomal dominant mode of inheritance $(7,8)$, the genes involved in the pathogenesis of radial polydactyly remain unclear. Therefore, classification of radial polydactyly is commonly based on the anatomy and site of the affected lesions (9), rather than on the basis of genetic information. However, radial polydactyly has a wide variety of clinical manifestations, including simple bifid duplication, complete duplication, and complex duplication (such as triplication and triphalangism).

The Wassel classification is largely applicable for classification of simple radial duplication (9), however, it is not suitable for complex radial polydactyly with involvement of triphalangism and triplication. In the present study, 7 of the 9 affected individuals had radial polydactyly including triplication, and all the affected individuals had triphalangeal thumb at different levels, with the exception of patient V5. Therefore, the Wassel classification was not suitable for defining the phenotypes of the affected individuals in this family due to their complex phenotype. Zuidam et al. subsequently proposed a modified classification system, which integrated the Wassel and Buck-Gramcko (10) classifications, for radial polydactyly with components of triphalangism and triplication (11). The Zuidam classification provides for a more precise description of complex radial polydactyly. 
Table 1 Summary of the phenotypes of the affected individuals in the family, including thumb duplication, syndactyly, triphalangism, and ulnar polydactyly

\begin{tabular}{|c|c|c|c|c|c|c|c|}
\hline No. & Age & Sex & Radial polydactyly & Triphalangeal thumb & Triplication & Syndactyly & Ulnar polydactyly \\
\hline III-3 & 71 & M & + & + & + & + & + \\
\hline IV-2 & 53 & $\mathrm{~F}$ & + & + & + & - & - \\
\hline IV-3 & 48 & $\mathrm{~F}$ & + & + & + & + & - \\
\hline IV-11 & 52 & M & + & + & + & + & - \\
\hline V-2 & 31 & M & + & + & + & - & - \\
\hline V-5 & 28 & M & - & - & - & + & - \\
\hline VI-1 & 3 & M & + & + & + & + & + \\
\hline
\end{tabular}

$\mathrm{F}$, female; M, male.
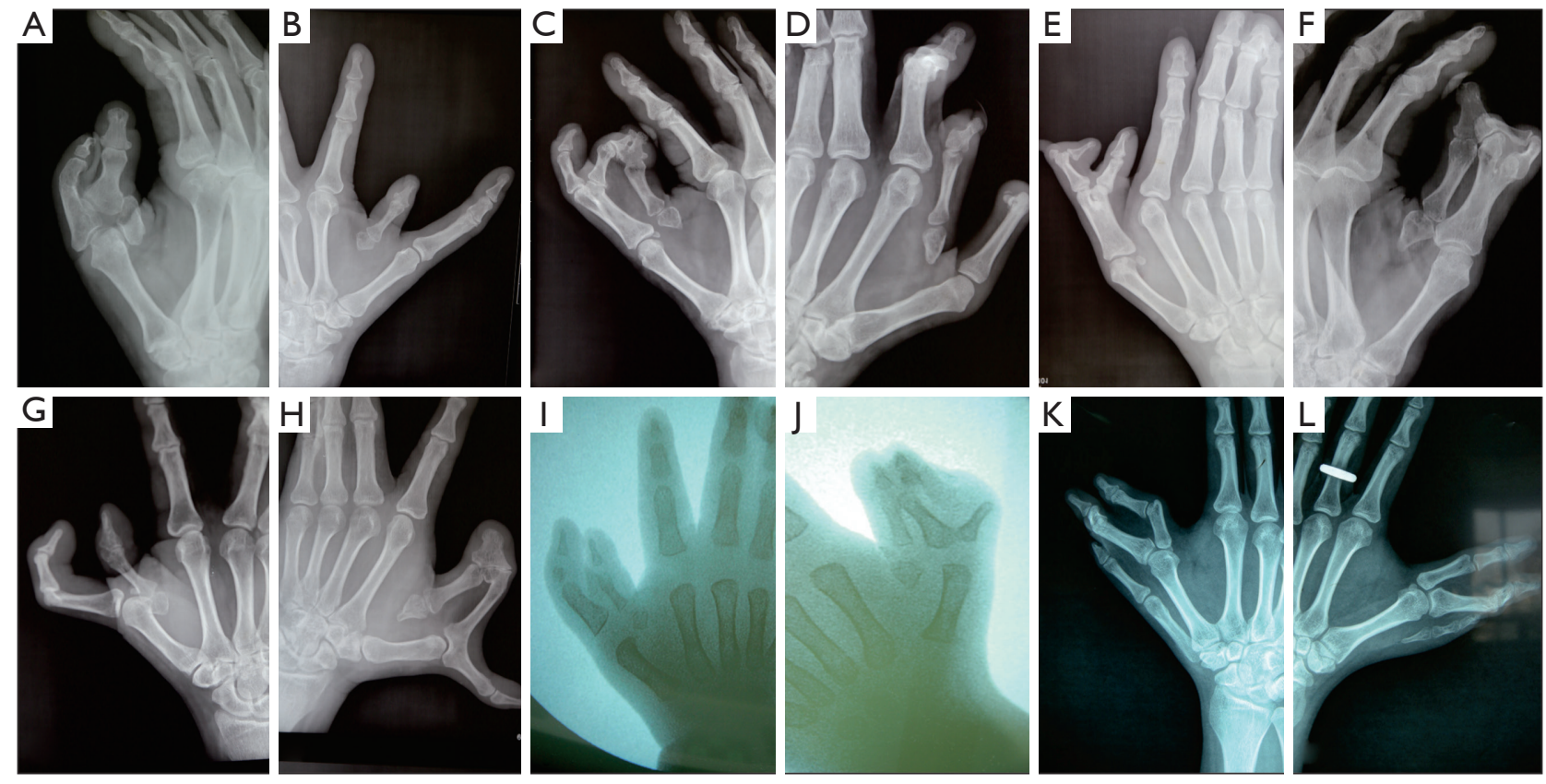

Figure $4 \mathrm{X}$-ray radiographs showing the various phenotypes of the thumb of the affected individuals. (A) Triphalangism and hypolastic; (B) triphalangism and hypolastic; (C) triphalangism, symphalangism, and hypolastic; (D) hypolastic; (E) triphalangism and symphalangism; (F) triphalangism, symphalangism, and hypolastic; $(\mathrm{G})$ triphalangism and hypolastic; $(\mathrm{H})$ triplication, triphalangism, symphalangism, and hypolastic; (I) triphalangism and hypolastic; (J) triplication, triphalangism, and hypolastic; (K) triplication; (L) triplication and hypolastic.

In addition to the complex manifestations of thumb duplication, most of the affected persons had syndactyly, which was classified, according to the Temtamy-McKusick classification (12), as complex syndactyly involving fusion of both bony and soft tissues of the third to the fifth digits and simple incomplete syndactyly involving fusion of the body or soft tissues between the third and fourth digits. Mixed complete and incomplete syndactyly was also observed in two patients. Therefore, these patients were better categorized as complex radial polydactyly with components 

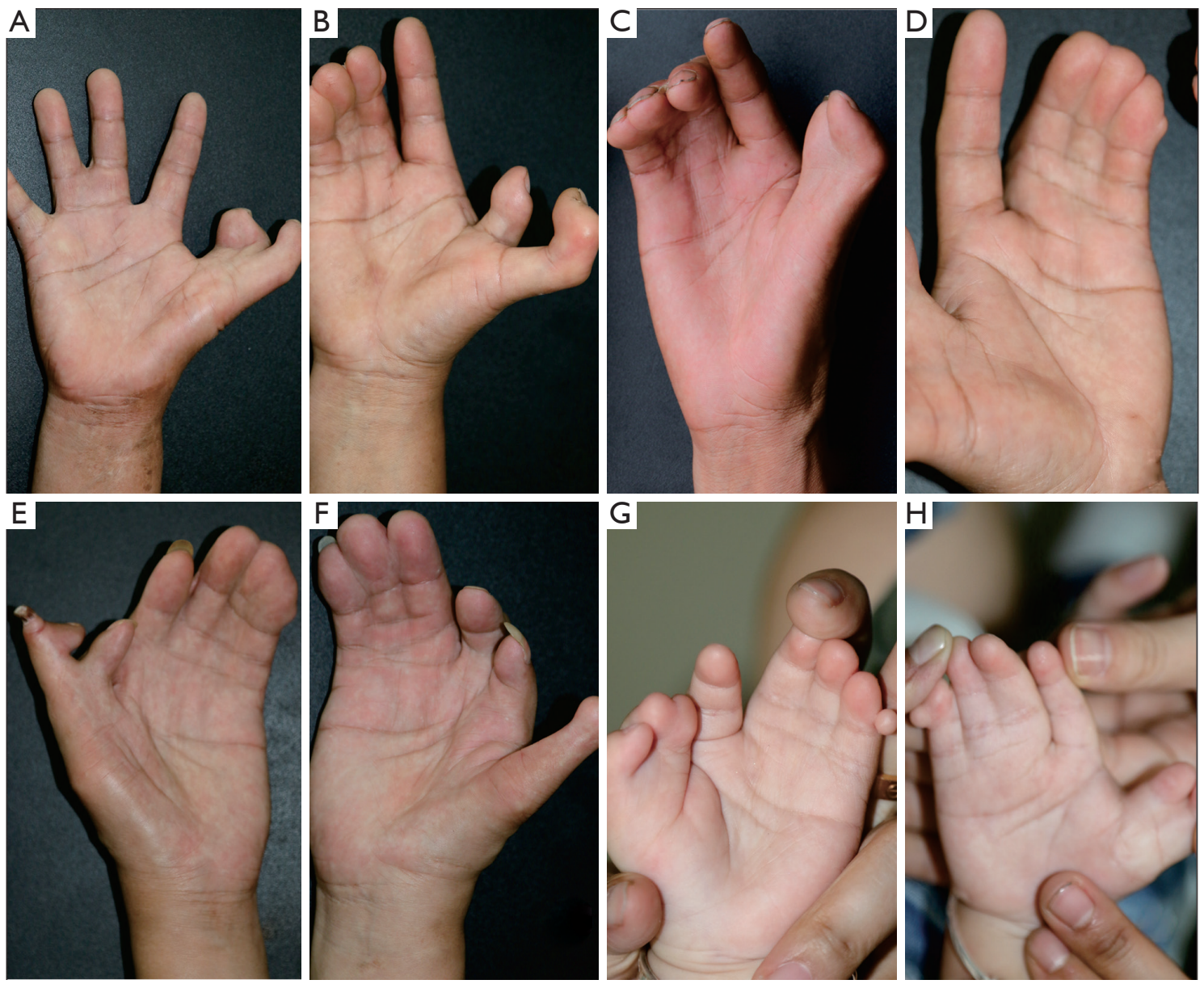

Figure 5 Complex and simple incomplete types of syndactyly in the family. (A) Simple incomplete syndactyly; (B-F) complex syndactyly; $(\mathrm{G}, \mathrm{H})$ simple complete syndactyly between the third and fourth digits, and simple incomplete syndactyly between the fourth and fifth digits.

of triphalangism, triplication, and syndactyly. These types of cases have been rarely reported in the literature and may represent a rare type of polydactyly.

Most of the polydactylies are due to the disruption of the anterior-posterior (AP) polarization of the limb bud. The disease could be part manifestation of a syndrome or an isolated form. Genetic factors account for the main cause of polydactyly, and environmental factors are less likely involved. Most non-syndromic polydactyly show an autosomal dominant inheritability. Hence, single gene mutation is enough to induce the disease. To date, there are at least 25 genes and loci associated with polydactyly in databases (HGMD, OMIM, and PubMed).

Mutation and duplication of the zone of polarizing activity regulatory sequence (ZRS), an enhancer of sonic hedgehog $(\mathrm{SHH})$, are known to contribute to the pathogenesis of radial polydactyly (13). The ZRS is located within intron 5 of the LMBR1 gene on chromosome $7 \mathrm{q} 36.3$ (14), and plays an important role in the regulation of its target gene $S H H$ that determines the number of digits during early limb development (15). Mutations in ZRS can increase Shb gene expression, thus resulting in polydactyly in many species, including mice, dogs, cats, chickens, and humans $(16,17)$. Studies have shown that mutations and duplication of the ZRS may result in various phenotypes including triphalangism and syndactyly (18-20). Recent reports have described an association of mutations in the pre-ZRS region with polydactyly $(21,22)$. In addition, ZRS can cause human syndactyly and triphalangeal thumb-polysyndactyly syndrome (TPTPS) in Chinese families $(18,19,23)$. The syndrome has an autosomal-dominant mode of inheritance and is characterized by anomalies of the upper extremity, 
A

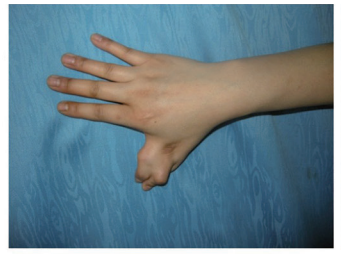

B

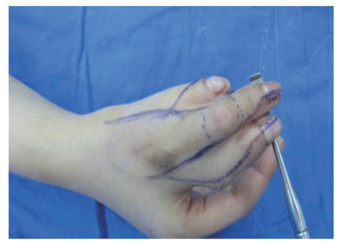

$\mathrm{D}$

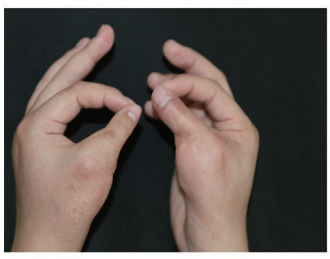

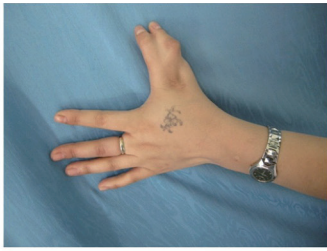
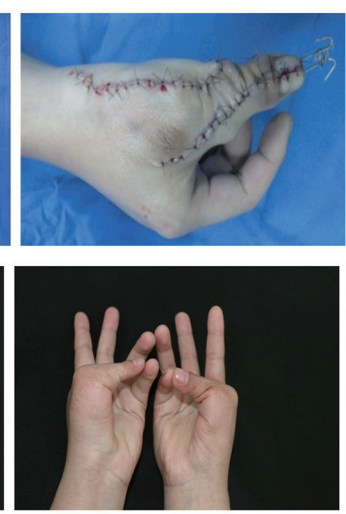

E

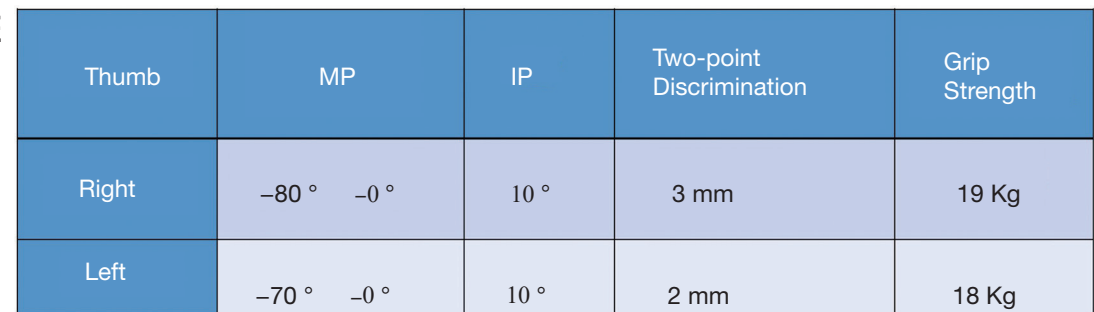

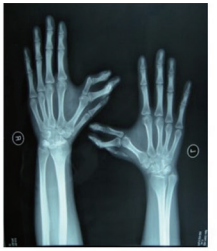
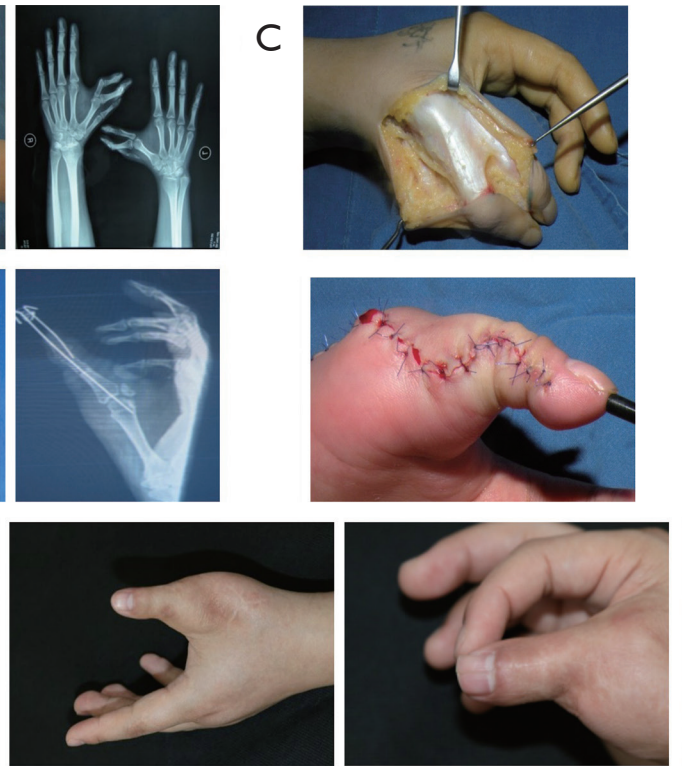

$\mathrm{F}$

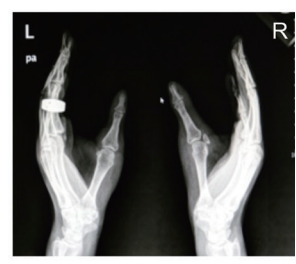

Figure 6 A 25-year-old woman with complex thumb duplication. (A) Preoperative optical photographs and X-ray radiographs showing radial polydactyly with triphalangism and triplication. (B) Images of hands with marks for the incision before the first surgical treatment to resect the radial supernumerary thumb (right), after surgery (middle), and postoperative $\mathrm{X}$-ray radiographs (left). (C) Images of hands during the second surgical treatment to resect the radial supernumerary thumb showing the exposure of the thumb (above) and the postoperative image (below). (D) Images showing the functional recovery of the thumb at 8 years post-surgery. (E) Functional evaluation of the hands. (F) Follow-up X-ray radiograph at 8 years after surgery.

mainly manifesting as one or more similar structures with three fingers in the thumb position, co-existing between the third and fifth fingers, and less involvement of the second finger. Therefore, further studies should be performed to detect potential mutations and/or duplications in the ZRS region in this Chinese family.

Surgical resection of extra digits to achieve mobility of the thumb is the main treatment option for radial polydactyly (24). Since the ulnar thumb is better developed, the radial thumb is typically resected in patients with radial polydactyly. For patients V2 and VI, the radial supernumerary thumbs were resected via two osteotomies. In addition, the ulnar thumb was preserved owing to the benefit of preservation of the ulnar collateral ligament, which is important for grip and pinch. For these patients, the thumb function, such as two-point discrimination and grip, were well recovered, even at 8 years post-surgery for patient V2.

\section{Conclusions}

In summary, this study described a Chinese family with nine individuals across six generations affected by complex radial polydactyly. This case series exhibited various mixed phenotypes, including thumb duplication, syndactyly, triphalangism, and ulnar polydactyly. Importantly, variable phenotypes are expected in diseases with an autosomal dominant mode of inheritance, and this could be attributed to gene modifiers, epigenetic influences, or environmental factors. Further studies should be performed to detect the 

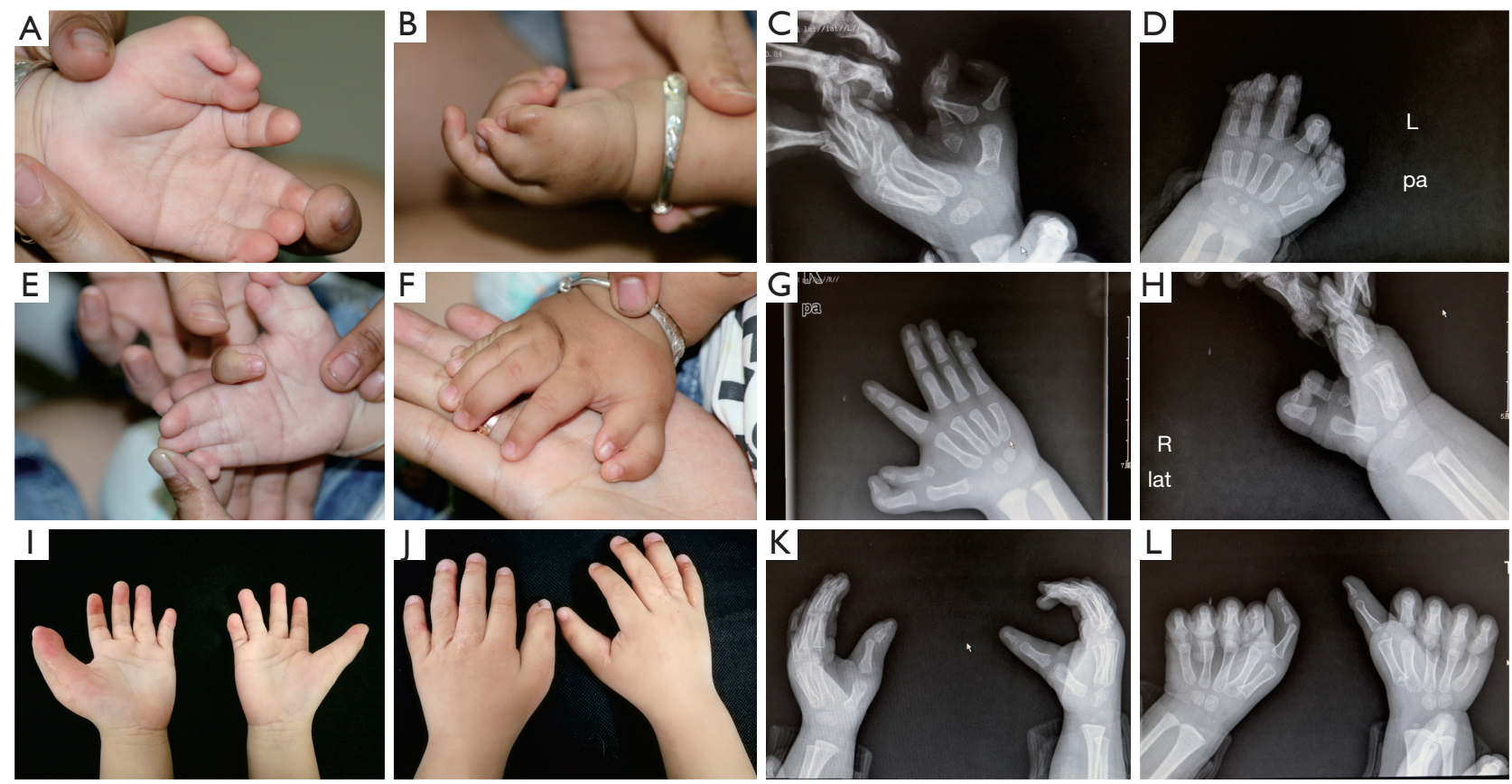

Figure 7 A 3-year-old boy with complex thumb duplication. (A-H) Preoperative optical photographs showing radial polydactyly with triphalangism, triplication, and syndactyly. (I-L) Postoperative optical photographs showing normal function of the hand at the 1-year follow-up.

potential genetic causes that led to the complex phenotypes of polydactyly in this large Chinese family.

\section{Acknowledgments}

Funding: This research was supported by research a grant from Zhejiang Province Health project (2021KY1061).

\section{Footnote}

Reporting Checklist: The authors have completed the MDAR reporting checklist. Available at https://dx.doi. org/10.21037/atm-21-2773

Data Sharing Statement: Available at https://dx.doi. org/10.21037/atm-21-2773

Conflicts of Interest: All authors have completed the ICMJE uniform disclosure form (available at https://dx.doi. org/10.21037/atm-21-2773). The authors have no conflicts of interest to declare.

Ethical Statement: The authors are accountable for all aspects of the work in ensuring that questions related to the accuracy or integrity of any part of the work are appropriately investigated and resolved. All procedures performed in this study involving human participants were in accordance with the Declaration of Helsinki (as revised in 2013). The study was approved by the Ethical Review Committee of the Ningbo No. 6 Hospital (SX201950) and informed consent was taken from all the patients.

Open Access Statement: This is an Open Access article distributed in accordance with the Creative Commons Attribution-NonCommercial-NoDerivs 4.0 International License (CC BY-NC-ND 4.0), which permits the noncommercial replication and distribution of the article with the strict proviso that no changes or edits are made and the original work is properly cited (including links to both the formal publication through the relevant DOI and the license). See: https://creativecommons.org/licenses/by-nc-nd/4.0/.

\section{References}

1. Piette N, Zambelli PY, N'Dele D. Isolated heptadactylia: A case report of central polydactyly of the foot. Medicine 
(Baltimore) 2017;96:e8324.

2. Cocciadiferro D, Agolini E, Digilio MC, et al. The splice c. $1815 \mathrm{G}>\mathrm{A}$ variant in KIAA0586 results in a phenotype bridging short-rib-polydactyly and oral-facial-digital syndrome: A case report and literature review. Medicine (Baltimore) 2020;99:e19169.

3. Watt AJ, Chung KC. Duplication. Hand Clin 2009;25:215-27.

4. Zhou GX, Dai L, Zhu J, et al. Epidemiological analysis of polydactylies in Chinese perinatals. Sichuan Da Xue Xue Bao Yi Xue Ban 2004;35:708-10.

5. Van Wyhe RD, Trost JG, Koshy JC, et al. The Duplicated Thumb: A Review. Semin Plast Surg 2016;30:181-8.

6. Al-Qattan MM. The association between preaxial polydactyly and radial longitudinal deficiency in syndromic cases: a report on nine families. J Hand Surg Eur Vol 2018;43:744-50.

7. Agsalda-Garcia M, Shieh T, Souza R, et al. RamanEnhanced Spectroscopy (RESpect) Probe for Childhood Non-Hodgkin Lymphoma. SciMed J 2020;2:1-7.

8. Zhang SJ, Clark M, Liu X, et al. The Effects of Bio-inspired Electromagnetic Fields on Healthy Enhancement with Case Studies. Emerging Science Journal 2019;3:369-81.

9. Wassel HD. The results of surgery for polydactyly of the thumb. A review. Clin Orthop Relat Res 1969;64:175-93.

10. Lay-Khim G, Bit-Lian Y. Simulated Patients' Experience towards Simulated Patient-Based Simulation Session: A Qualitative Study. SciMedicine Journal 2019;1:55-63.

11. Zuidam JM, Selles RW, Ananta M, et al. A classification system of radial polydactyly: inclusion of triphalangeal thumb and triplication. J Hand Surg Am 2008;33:373-7.

12. Malik S. Syndactyly: phenotypes, genetics and current classification. Eur J Hum Genet 2012;20:817-24.

13. Maas SA, Fallon JF. Isolation of the chicken Lmbr1 coding sequence and characterization of its role during chick limb development. Dev Dyn 2004;229:520-8.

14. Lettice LA, Heaney SJ, Purdie LA, et al. A long-range Shh enhancer regulates expression in the developing limb and fin and is associated with preaxial polydactyly. Hum Mol

Cite this article as: $\mathrm{Xu} \mathrm{J}$, Chen $\mathrm{X}$, Teng $\mathrm{X}$, Wang $\mathrm{X}$, Chen H. Complex radial polydactyly in a Chinese family: inclusion of triphalangism, triplication, and syndactyly. Ann Transl Med 2021;9(16):1296. doi: 10.21037/atm-21-2773
Genet 2003;12:1725-35.

15. Riddle RD, Johnson RL, Laufer E, et al. Sonic hedgehog mediates the polarizing activity of the ZPA. Cell 1993;75:1401-16.

16. Li H, Wang CY, Wang JX, et al. Mutation analysis of a large Chinese pedigree with congenital preaxial polydactyly. Eur J Hum Genet 2009;17:604-10.

17. Lettice LA, Hill AE, Devenney PS, et al. Point mutations in a distant sonic hedgehog cis-regulator generate a variable regulatory output responsible for preaxial polydactyly. Hum Mol Genet 2008;17:978-85.

18. Wu L, Liang D, Niikawa N, et al. A ZRS duplication causes syndactyly type IV with tibial hypoplasia. Am J Med Genet A 2009;149A:816-8.

19. Sun M, Ma F, Zeng X, et al. Triphalangeal thumbpolysyndactyly syndrome and syndactyly type IV are caused by genomic duplications involving the long range, limbspecific SHH enhancer. J Med Genet 2008;45:589-95.

20. Wieczorek D, Pawlik B, Li Y, et al. A specific mutation in the distant sonic hedgehog $(\mathrm{SHH})$ cis-regulator (ZRS) causes Werner mesomelic syndrome (WMS) while complete ZRS duplications underlie Haas type polysyndactyly and preaxial polydactyly (PPD) with or without triphalangeal thumb. Hum Mutat 2010;31:81-9.

21. Potuijt JWP, Baas M, Sukenik-Halevy R, et al. A point mutation in the pre-ZRS disrupts sonic hedgehog expression in the limb bud and results in triphalangeal thumb-polysyndactyly syndrome. Genet Med 2018;20:1405-13.

22. Xiang $Y$, Jiang L, Wang B, et al. Mutational screening of GLI3, SHH, preZRS, and ZRS in 102 Chinese children with nonsyndromic polydactyly. Dev Dyn 2017;246:392-402.

23. Dai L, Guo H, Meng H, et al. Confirmation of genetic homogeneity of syndactyly type IV and triphalangeal thumb-polysyndactyly syndrome in a Chinese family and review of the literature. Eur J Pediatr 2013;172:1467-73.

24. Dijkman RR, van Nieuwenhoven CA, Hovius SE, et al. Clinical Presentation, Surgical Treatment, and Outcome in Radial Polydactyly. Handchir Mikrochir Plast Chir 2016;48:10-7. 